\section{From Ethnic to Interethnic}

\section{The Case for Identity Adaptation}

\section{and Transformation}

\author{
Young Yun Kim \\ University of Oklahoma, Norman
}

The academic literature for the past several decades suggests an increased tendency to conceive "ethnic identity" as an a priori and morally inviolable human condition exclusively attributed to a social group identified by birth or ascription. Paralleling this trend is a gradual shift toward a more pluralistic ideology of interethnic relations and toward a greater emphasis on political activism in social research. In this historical context, the article identifies two interrelated problematics in the prevailing pluralistic conceptions of ethnic identity: positivity bias and oversimplification. These problematic aspects are examined against the well-documented individual and situational variations in ethnic identity. As a way to counterbalance and complement the pluralistic conceptions, a theoretical account for the process of identity transformation is offered. This dynamic theory highlights the experiences of many individuals who, through their communication activities of crisscrossing ethnic boundaries, have moved beyond the perimeters of a single ethnic category in their identity orientations.

Keywords: stress; adaptation; growth; identity transformation; interethnic identity

$\mathrm{W}$

e live in an era of clashing ethnic identities. The tightly knit system of communication and transportation has brought differing languages, religions, cultures, races, and nationalities closer than ever before in a web of interdependence and a common fate. Rigid adherence to the ethnic identity of our youth is no longer feasible as culture in its "pure" form has become more a nostalgic concept than a reality. As Toffler (1980) noted, we find ourselves "[facing] a quantum leap forward. [We face] the deepest social upheaval and creative restructuring of all time. Without clearly recognizing it, we are engaged in building a remarkable new civilization from the ground up" (p. 44). Paradoxically, the very forces that diminish physical boundaries exacerbate ethnic and national rivalries, rendering the deeply fractious and

\footnotetext{
Author's Note: This article elaborates on, and extends, the remarks that the author made in the symposium "Philosophical and Ideological Underpinnings of Inquiry Into Cultural Identity," presented during the Ninth International Conference on Language and Social Psychology. The author acknowledges the other three participants in this symposium-Donal Carbaugh, Richard Clément, and Cynthia Galloisand the thoughtful and thought-provoking ideas each of them offered with respect to the symposium theme. Correspondence may be addressed to Young Yun Kim, Department of Communication, University of Oklahoma, Norman, OK 73071; e-mail: youngkim@ ou.edu.
} 
unsettling landscape of today's world. The seemingly innocent banner of ethnic identity is now a compelling sore spot galvanizing many into "us-against-them" posturing. Some of the most passionate domestic and international conflicts headlining the daily media involve differing ethnic identities, particularly along linguistic, tribal, racial, and religious lines. From long-festering prejudices, discriminations, and hatreds to the more recent acts of violent rage and terror, we are seeing in all corners of the world so many angry words, so much hurt, and so much destruction.

In this fractured landscape, the "diversity" or "multiculturalism" embraced in many societies is as much a point of tension, contention, and terror as it is a cause celebre. The relatively simple civic consensus in the vision of diverse yet peaceful and democratic societies is being severely challenged by one that upholds ethnic identity side by side, if not in place of, the larger identity of citizenry. Often absent in the identity polemics are the main ideals of multiculturalism itself: that people with different roots can coexist; that they can learn from each other; and that they can, and should, look across and beyond the frontiers of race and ethnicity (as well as gender and other social categories) with minimum prejudice or illusion and learn to think against the background of an integrated society of true multiculturalism. Even more important, the current polemics seem to deny the fact that some of the most interesting things of all in human history and its remarkable stability and peace have happened, in fact, at the free and democratic interface of differing ethnic roots.

In this global context, some important questions need to be posed. At what point, for example, do people cross the line from rightful and constructive claims for group identity to disastrous intergroup collisions with undue prejudice directed against one another? Can the desire for some form of collective uniqueness be satisfied without resulting in divisions and conflicts among groups? How can a society of multiple ethnic identities support and give confidence to all groups while upholding the communal responsibilities that transcend allegiance to each group? Can a society, and the world, achieve this goal in spite of the increasing trend of disunity and "unbounded and unwholesome pluralism" (Etzioni, 1993, p. 217)?

Pragmatic concerns such as these underpin, and signify, the main aim of this theoretical article, that is, to make a case for an identity that transcends ethnic categories by bringing into focus and highlighting the adaptive and transformative nature of identity. With this aim, the author examines the trend in the literature for the past several decades toward an increasingly pluralistic conception of ethnic identity by birth or ascription. This trend is discussed in light of the gradual shift in political ideology toward pluralism, on one hand, and in the increase in interest and emphasis on political activism in social research, on the other. Based on this historical examination of academic conceptions of ethnic identity, the author makes a case for greater recognition and understanding of the complexity, dynamism, and open-ended nature of the identity experiences of many - the changing nature of ethnic identity that has been left largely unrecognized in the contemporary academic discourse on ethnic identity. 
The term ethnic identity is employed in this article as a broad, inclusive concept that represents similar terms such as national, cultural, ethnolinguistic, racial, and religious identity, following the common usage of the term among social scientists (Yinger, 1986, p. 22). Ethnic identity designates both a sociological or demographic classification as well as an individual's psychological identification with, or sense of belonging to, a particular ethnic group. The psychological and sociological meanings of ethnic identity are regarded as two inseparable correlates of the same phenomenon. In addition, the term interethnic identity, is employed as a counterpoint to, and an extension of, ethnic identity. This concept highlights the phenomenon of identity adaptation and transformation explained later in this article.

\section{Pluralism and Ethnic Identity}

From the early years of the 20th century (e.g., Schuetz, 1944/1963; Simmel, 1908/1950; Stonequist, 1937), and particularly for the past several decades, the notions of identity, in general, and ethnic identity, in particular, have occupied a central place in behavioral and social sciences. Systematic investigations of ethnic identity can be traced back to psychologist Erickson's $(1950,1968)$ important early theoretical framework. Erickson described the process of identity development as one in which the two identities - of the individual and of the group - are merged into one. Erickson placed ethnic identity at the core of the individual and yet also in the core of his or her "common culture." Erikson's early identity conception has been echoed in subsequent academic writings about ethnic identity. For De Vos (1990a), for example, ethnic identity provides "a sense of common origin, as well as common beliefs and values, or common values" and serves as the basis of "self-defining in-groups" (p. 204). For Yinger (1986), ethnic attachment is a "genuine culture" that forms the person's "basic identity" and offers "a sense of historical continuity and embeddedness and a larger existence in a collectivity of one's group" (p. 21).

Because of the inseparability of the personal and the social in these conceptions, ethnic identity has been approached primarily as a group-level phenomenon in anthropological and sociological studies. Cultural anthropologists conceive ethnicity as a kind of temporal continuity or common tradition linking its members to a common future (Nash, 1989), reflected in the communal life patterns associated with language, behavior, norms, beliefs, myths, and values, as well as the forms and practices of social institutions. In sociological research, ethnicity is commonly treated as a social category defined by membership that is differentiated from other groups by a set of objective characteristics, qualities, or conditions such as national and/or geographical origin, language, religion, race, and culture. This is the way, for instance, sociologists such as Glazer and Moynihan (1975) investigated the phenomenon of "ethnic stratification" in the United States. 
Psychological studies, on the other hand, typically approach ethnic identity in terms of "the subjective orientation of an individual toward his or her ethnic origins" (Alba, 1990, p. 25). Terms such as ethnic identity, ethnolinguistic identity, or ethnic identification are often exchangeably used to replace ethnicity per se in most social psychological studies of intergroup behavior. From the perspective of the influential social identity theory (Tajfel, 1974, 1978; Tajfel \& Turner, 1979, 1986), ethnic identity is seen as "that part of an individual's self-concept which derives from his knowledge of his membership in a social group (or groups) together with the value and emotional significance attached to that membership" (Tajfel, 1978, p. 63). The social identity theory and many experimental studies based on this theory (e.g., Brewer \& Miller, 1984; Tajfel \& Turner, 1979, 1986) further illuminate the interplay of the two dimensions of personhood, the personal and the social. That is, identification with a social group is rooted in the basic human tendency of cognitive categorization, and the membership in, and identification with, an ethnic group renders the individual an emotionally significant aspect of the individual's self-concept. Collective interests are of concern to the individual, above and beyond their implications for personal self-interest. Ethnic identity, in effect, is deemed an extension of the self; it entails "a shift towards the perception of self as an interchangeable exemplar of some social category and away from the perception of self as a unique person" (Turner, Hogg, Oakes, Reicher, \& Wetherell, 1987, p. 50).

\section{The Pluralistic Turn}

The emphasis placed on the importance of positive ethnic identity has continued in recent decades. Giordano (1974), for instance, saw it as a psychological foundation offering the individual a "ground on which to stand" that "no one can take away" (p. 16). For Roosens (1989), ethnic identity is "the driving force of individual and collective ethnic self-affirmation" (p. 15). For De Vos (1990b), ethnic identity is rooted in "the emotionally profound 'self-awareness' of parentage and a concomitant mythology of discrete origin" (p. 14).

Such idealized or essentialist conceptions of ethnic identity parallel the ideological shift toward greater pluralism and multiculturalism in the United States, beginning with the "new ethnicity" movement prompted by the civil rights movement in the 1960s in the United States. (See Kim [1999, 2002] for a detailed examination of the competing ideological perspectives in the United States at large and in the academic conceptions of ethnic identity in particular.) In their early work, Glazer and Moynihan (1963) concluded a sociological analysis by stating that ethnicity pervades all spheres of life among ethnic minorities: "The point about the melting pot is that it did not happen" (p. 290). Others (e.g., Greeley, 1974; Parenti, 1967; Wolfinger, 1965) found that ethnic minorities in the United States possessed political orientations different from those of mainstream Americans, evidenced in respective 
voting patterns that persisted for many generations. Novak (1971) argued against assimilation and advocates "equal ethnicity for all." He described the feelings of alienation held by one large ethnic group, Poles, who had been drawn to "ethnic power" movements in the competition for jobs, respect, and attention.

The pluralistic turn in academic conceptions of ethnic identity has capitalized on the inherent and profound dilemma, that is, a contradiction arising from the inevitable gap between the assimilationist emphasis on transcending group categories and the reality of everyday life in which group categories continue to constrain ethnic minorities. In this movement, the primacy of individual identity has been challenged by contrary claims of group identity and the associated attempts to elevate group and cultural distinctiveness over a larger, national identity. It, thereby, has replaced the traditional "melting-pot" metaphor with newer ones such as "mosaic," "quilt," and "salad bowl." Underlying the pluralistic, group-based construction of personhood and society is the world view of relativism that de-emphasizes universalities while emphasizing group differences in human conditions, particularly in languages and religious traditions.

Side by side with the pluralistic turn in the United States, we have seen an increasing trend of departure in research addressing issues of ethnic identity from the traditional normative-representational stance of value-neutrality to the stance of political advocacy and other forms of practice. This politicization of academic research on ethnic identity is reflected in the increasing number of traditional social scientists, who are committed to the "liberal" ideals of diversity and social justice and find the principally value-neutral stance of the traditional scientific approach less than satisfying (Billig et al., 1988; Diesing, 1991; Graff, 1992; Hammersley, 1995; Thornton, 1996). Today, arguments are often made by some for a redistribution of power and resources to overcome inequalities in group status (e.g., Hacker, 1992) and for a greater diversity of the university curriculum by replacing it with one "that would focus on the achievements of marginalized peoples and on the sins of the nation's founders" (Traub, 1998, p. 25).

The shift in emphasis from theory to political activism has been fueled by nontraditional scholars of various postmodern philosophical schools such as "critical theory," "cultural studies," and "muted group and standpoint theory," among others (Hammersley, 1995, p. x). They have been mounting vigorous arguments to gear research directly to "emancipatory" political goals of eliminating "White racism" at home and countering Western/American "imperialism" abroad. Indeed, pressure has been felt by many traditional researchers who find the field too political, so much so that a given theory, along with the credibility of the theorist, appears to be dismissed by some, not based on the validity of the knowledge claim in representing the reality in question, but simply based on the implied question, "Whose side are you on?"

Tsuda (1986), for instance, criticized the Western ideological domination as the genesis of "distorted intercultural communication" around the world. Tsuda argued, in particular, that the dominance of English language embodies the dominance of Western ideology, which imposes an overt restriction on non-Western peoples' freedom of 
expression and damages their identity. Likewise, Young (1996) presented his criticism of Western "cultural imperialism" by depicting today's global reality as one of power asymmetry between communicators rooted in "oppressive" and "imperialistic" Western cultural-institutional systems. Young further argued that only when we understand "the process through which cultural exclusion and manipulation of identity of culturally different people is carried out in everyday communication" can we have a clear basis for "effective politics aimed at changing empirically observable mechanisms for the creation of ideology or the assertion of the reality of one culture over another" (p. 29).

\section{Problematics in Pluralistic Conceptions}

Few informed individuals would doubt that, under certain circumstances such as past and present intergroup competitions and hostilities, ethnic group identity can significantly influence the way people feel about themselves, about their in-groups, and about target out-groups. One can also see the practical advantage of collective empowerment by solidifying group identity to serve the end of correcting historical and institutional injustices based on group categories. At the same time, however, the prevailing pluralistic conceptions of ethnic identity present at least two interrelated problems: (a) positivity bias and (b) oversimplification.

Almost invariably in pluralistic conceptions, there is a common presumption of positive values and unconditional moral imperative in characterizing the nature of ethnic identity. Pluralistically inclined social scientists, not to mention postmoderncritical scholars, have been largely silent about the "dark side" of ethnic identity-the tendencies of collective self-glorification and denigration of other groups. An insufficient amount of attention has been given to the fact that too strict an adherence to an ethnic identity can raise fear and distrust of other groups, reinforce separatist sentiments, and thus lower the possibility of cooperative intergroup actions. Intended or not, some critical researchers' writings suggest a sense of "ethnic identity at any cost." Ethnic identity is not only to be recognized, preserved, and respected but also to be a means to combat unjust practices. Ethnic groups are deemed inherently equal in their original states, but their original natures are seen as being distorted and corrupted in the process of interaction with others in society and through the development of sociocultural institutions (Tsuda, 1986, pp. 62-63). Here, equality is defined less in terms of fairness of rules, as in the procedural equality in the sense of classical liberalism, and more in terms of group status equality, particularly in terms of the inherent moral rights of all groups expressed in the "pride" and "dignity" of a people. The classical liberal constructs of individualism and universalism are deemed a false ideology in that it serves only the end of legitimizing the capitalist system of "winners" and "losers" in society.

The attribution of a positive moral value to ethnic identity is problematic in that it fails to acknowledge one of the basic tenets of the previously discussed social identity theory. That is, individuals identify with a group in a manner that serves 
positive self-identity. The way people experience ethnic identity is essentially emotionally driven. This further means that, when it comes to our relationships to out-groups in competition or conflict, we are less than likely to be fair and objective and more likely to be irrational, defensive, and self-serving, favoring our ingroup and discriminating against the out-group that threatens our in-group. The identity boundaries are seen as something everyone is, and must be, reluctant to compromise.

Closely linked to the problem of attributing positive moral values to ethnic identity is the problem of oversimplification, particularly in the context of the United States. Many of the pluralistic conceptions portrays ethnic identity as an "all-ornone" or "either-or" entity that belongs exclusively to a category of people. A person is commonly viewed to develop and belong to one and only one particular ethnic group: If someone sees himself or herself or is seen by others as, say, a Mexican American, then this person's identity is viewed to exclude all other identities. The monolithic and static conceptions of ethnic identity are often reflected in statements that inflate uniformity among the individuals who are associated with a particular group. Some researchers have tended to lump together all individuals ascribed to a particular ethnic group and portray them as though they are a homogeneous group with identical characteristics. For example, Hacker (1992) described the contemporary Black as someone who is marginal, separate, and victimized in the White world, despite the many contrary statistics presented in his book.

Together, the positivity bias and oversimplification appear to reflect a political desire among those researchers of pluralistic beliefs to help emphasize identity maintenance of ethnic minorities and de-emphasize or neglect the phenomenon of integration and assimilation into the mainstream ethnic culture. In Pettigrew's (1988) words, "To many, talk of mosaics and quilts to emphasize the autonomous nature of identity and its relationships among cultural identities is both an attempt to describe the way America is headed and an effort to hurry it along" (p. 19).

\section{Complexities of Ethnic Identity}

At least in societies such as the United States, where individuals of diverse ethnic backgrounds routinely interact face to face or via exposures to mass media, the pluralistic value-laden and categorical characterizations belie the complexities in the way ethnic identity plays out in the grassroots reality.

\section{Individual and Situational Variations}

Various sources of information on demographic changes in the United States (e.g., Lind, 1995; Root, 1993; Smolowe, 1993) report that since the 1960s, about four fifths of Italian Americans, half of American Jews, one third of Hispanics, one 
half of Asian-Americans, and 70\% of Native American Indians have married outside their officially designated categories since 1950. During the 1970s and 1980s, the incidence of births of mixed-race babies multiplied 26 times as fast as that of any other group. Today, about half of Blacks, virtually all Latinos and Filipinos, the majority of American Indians and Native Hawaiians, as well as a significant proportion of White-identified persons are considered to be of multiracial-multiethnic origins. The number of children born to Black-White marriages quintupled between 1968 and 1988. It is not surprising, then, that a growing number of mixed-race Americans sought and got their own "multiracial" category in the 2000 U.S. Census question on race.

In addition, individuals with a common background significantly vary in the intensity of identification with and commitment to the collective experiences and goals, and in the degree to which their daily activities and accomplishments are bound up with their membership to that group. Many people's experience of ethnic identity is filled with trade-offs among multiple group identities or a merger thereof into a single selfhood. Findings from a survey of Hispanic Americans by Garza, DeSipio, Garcia, Garcia, and Falcon (1992) reveal such complexities in cultural identity. The study shows that the majority of Hispanic Americans feel at least as close to Anglos as they do to members of other Hispanic groups. Despite the strong fear expressed by those who adhere to identity maintenance at any cost, the study further indicates that a large majority of Hispanics are moving toward mainstream American culture and that $60 \%$ or more say the purpose of bilingual education is to learn both languages and less than $10 \%$ believe it is important "to maintain the Spanish language/culture." A majority of those surveyed further indicate their loyalties toward the United States, as a whole expressing very strong "love" and "pride" for the country.

Many existing theories in social psychology and intercultural communication address such individual variations in ethnic identity orientations. For example, Berry's $(1980,1990)$ psychological acculturation model identifies four identity orientations: "integration," "assimilation," "separation," and "marginalization." The varied orientations are explained in terms of the psychological relationships of individual immigrants and ethnic minorities toward their own ethnic group and toward the larger society. Identity variations are also noted in several models of "intercultural communication competence" or "effectiveness." Imahori and Cupach (2005) highlighted the fact that individuals are able to "manage" their ethnic identity when interacting with individuals of differing backgrounds, and that "facework" or the ability to "manage" each other's ethnic identity is a key to being a competent intercultural communicator. A similar identity conception underlies Ting-Toomey's $(1993,2005)$ theory, in which "identity negotiation" is placed at the center of "communicative resourcefulness" in intercultural encounters.

A more broadly based explanation of individual differences in identity orientation is suggested in a recent version of the communication accommodation theory 
(Gallois, Ogay, \& Giles, 2005). The theory explains that individuals of differing social identities do (or do not) accommodate each other when they interact and that the willingness to accommodate depends on sociohistorical factors (intergroup history, interpersonal history, and societal/cultural norms and values) as well as individual factors (e.g., initial intergroup or interpersonal psychological orientation). Another multidimensional theory has been proposed by this author (Kim, 1997, 2005b) to explain "associative" and "dissociative" communication behavior of individuals in interethnic encounters. The theory links associative-dissociative communication behavior to three layers of contextual factors: (a) communicator factors (including "identity strength" and "identity bias"), (b) situational factors (including "status equality/inequality" and "ethnic homogeneity/heterogeneity"), and (c) environmental factors (including "societal ideology" and "history of subjugation").

Theoretical models such as these are built on a nuanced and balanced conception of ethnic identity at the individual level. Although somewhat varied in focus, scope, and perspective, these theories address ethnic identity not as a fixed or monolithic psychological entity but as flexible and varied across individuals and situations. By conceiving ethnic identity as a "variable," the theories account for both pluralistic and assimilationistic possibilities, as well as other variants such as integrationist or separatist possibilities, in the enactment of ethnic identity in situations of interethnic contact and communication.

\section{Identity Adaptation and Transformation}

The complexities of ethnic identity increase further when we consider the phenomenon of adaptive changes in individuals' psychological orientations over time. Interethnic interactions often present challenges as people try to accommodate, understand, cooperate, and develop relationships with people of differing ethnic identities. As we take on these challenges, our own conceptions of who we are vis-à-vis our ethnicities may need to be adapted and transformed. Ethnic identity and adaptation are increasingly becoming an everyday experience of many people who crisscross multiple sets of identity boundaries.

As explained in the author's theory of cross-cultural adaptation (Kim, 1988, 1995, 2001, 2005a), the nature of a person as an open system is not fixed by birth but evolves throughout life. Each new experience in some way facilitates this evolution. Plasticity, the ability to learn and change through new experiences, is one of the most profound characteristics of the human mind. It is the very basis upon which individuals acquire an identity of self that incorporates various elements of an ethnically diverse environment. In this process, the identity becomes increasingly inclusive with a greater capacity to make deliberate choices of actions in specific situations rather than simply being dictated by the prevailing norms of the culture of childhood or by the dictates of the ethnic category ascribed to the individual. 
The theory emphasizes that interethnic experiences are often far from smooth or easy. Communicating across ethnic boundaries presents multitudes of difficulties, particularly when it necessitates learning a new language or compromising some of the deeply held beliefs. The extent of such challenges is partly a function of the degree of "ethnic distance" (or "ethnic proximity") that needs to be bridged, coupled with the uncertainty and unfamiliarity stemming from such cultural and linguistic difference, as well as the "intergroup posturing" of attitudes and actions based on "us-and-them" group-based perceptions. Moments of intense stress can reverse the process of identity transformation at any time; individuals may regress toward reidentifying with their origins, having found the alienation and malaise involved in maintaining a new identity too much of a strain. Such strain may take various forms of an identity conflict (Erickson, 1968) and marginality (Berry, 1980, 1990; Stonequist, 1964; Taft, 1977).

Typically in stressful situations, some kind of psychological maneuvering or "defense mechanism" is activated in individuals as they try to hold the internal structure constant: They may avoid or minimize the anticipated or actual "pain" of disequilibrium and stress by self-deception, denial, avoidance, and withdrawal (Lazarus, 1966, p. 262). Yet it is this very stress that "pushes" individuals to adjust and restructure their existing conditions to regain an internal balance and, in so doing, to realize an increased adaptation to the external challenge - $\mathrm{a}$ form of achieving what may be called the "inner alchemy" or the restoration of inner cohesiveness. The greater the challenges one encounters in interethnic communication experiences, the more profound the opportunity for new learning such experiences would present. This seemingly paradoxical principle suggests the unity in which stress and adaptation are inseparable: Adaptation occurs because of the stress and cannot occur without the stress. The interrelatedness of stress and adaptation describes the process of organizing and reorganizing oneself-the process that, in the context of interethnic interface, involves continual reinventing of an inner self beyond the boundaries of the original cultural identity. In this process, an identity is transformed, gradually and imperceptibly, from an "ascribed" to a newly "achieved" identity. As the "old" person breaks up, new knowledge, attitudes, and behavioral elements are assimilated into an enactment of growth - an emergent interethnic personhood at a higher level of integration.

The stress-adaptation-growth dynamic underlies a continual dialectical process of push and pull, or identity engagement and disengagement. As shown in Figure 1, the dynamic lies at the heart of interethnic identity development in the forwardupward movement of a cycle of "draw-back-to-leap." Each stressful experience is responded to with a "draw back," which then activates one's adaptive energy to "leap forward." The shifting between the breakup of the old identity and the creation of a new identity enables the individual to better adapt to subsequent interethnic encounters with a creative courage and resourcefulness (Slavin \& Kriegman, 1992).

The emerging "interethnic identity" is a special kind of mindset that promises greater fitness in our increasingly interfaced world. It represents a continuous struggle of searching for the authenticity in self and others within and across ethnic groups. It is a 
Figure 1

The Stress-Adaptation-Growth Dynamic

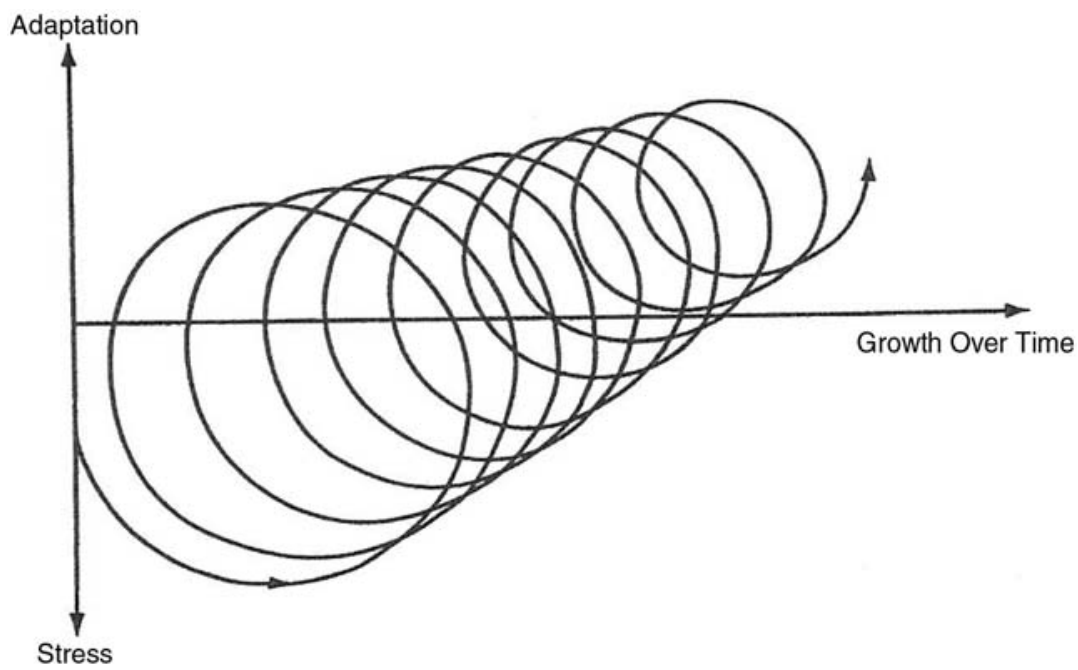

Source: $\operatorname{Kim}(2001$, p. 59).

way of existence that transcends the perimeters of a particular ethnic tradition and one that is capable of embracing and incorporating seemingly divergent ethnic elements into one's own unique worldview. The term interethnic identity is preferred here to highlight the open-ended generic nature of identity transformation rather than particular ethnic identities involved as suggested in related terms such as bilingual, biracial, bicultural, multilingual, multiracial, multicultural, and multiethnic identity.

One of the two key elements of interethnic identity development is an emerging self-other orientation that is individuated. Individuation involves a clear self-definition and definition of the other. It allows a person to relate to others without being rigidly constrained by the grips of conventional group categories. It establishes oneself and others on the basis of individual uniqueness rather than categorical group characteristics, reflecting a mental outlook that exhibits greater cognitive differentiation and particularization (cf. Billig, 1987; Boekestijn, 1988; Hansel, 1993; Oddou \& Mendenhall, 1984). Individuation is further expressed in a sense of oneself as the main agent of action and responsibility and of determination to "own" one's fate. Research findings provide direct and indirect evidence for individuation among those who are successfully adapted in a new cultural or subcultural environment. Amerikaner (1978) observed in a study of military cadets, seminarians, and college fraternity members that participants with a high degree of personality integration 
(measured by the ability "to deal effectively with everyday tensions and anxieties") exhibited greater cognitive differentiation and integration, less categorical and simplistic self-identity, and greater openness to new social experiences.

Accompanying individuation is universalization in self-other orientation, a parallel development of a mental outlook-a synergistic cognition "of a new consciousness, born out of an awareness of the relative nature of values and of the universal aspect of human nature" (Yoshikawa, 1978, p. 220). As we advance in the interethnic identity transformation process, we are better able to see the common humanity among different ethnicities and locate the points of consent and complementarity beyond the points of difference and contention. We are on the way to overcoming ethnic parochialism and forming a wider circle of identification and a vital outlook that is not locked in a provincial interest of one's own ascribed group membership, but one in which the individual sees himself or herself to be a part of a larger whole that includes other groups as well. This process of identity transformation "frees" us from an exclusive viewpoint, so as to attain a perspective that is less dualistic and more synergistic.

An eloquent personal testimonial for the above theoretical description of interethnic identity transformation is found in an essay by Louri (1993). The following excerpt from his reflection on his life experiences as a Black American echoes those of many others.

I have often experienced this dissonance between my self-concept and the socially imputed definition of who I am supposed to be. I have had to confront the problem of balancing my desire not to disappoint the expectations of others-both whites and blacks, but more especially blacks - with my conviction that one should strive to live life with integrity. . . . I no longer believe that the camaraderie engendered among blacks by our collective experience of racism constitutes an adequate basis for any person's self-definition. . . . The most important challenges and opportunities that confront me derive not from my racial condition, but rather from my human condition. I am a husband, a father, a son, a teacher, an intellectual, a Christian, a citizen. In none of these roles is my race irrelevant, but neither can racial identity alone provide much guidance for my quest to adequately discharge these responsibilities. The particular features of my social condition, the external givens, merely set the stage of my life, they do not provide a script. That script must be internally generated, it must be a product of a reflective deliberation about the meaning of this existence for which no political or ethnic program could ever substitute. . . . In my view, a personal identity wholly dependent on racial contingency falls tragically short of its potential because it embraces too parochial a conception of what is possible, and of which is desirable. (pp. 7-10)

\section{Beyond Ethnic Identity}

There is great uncertainty regarding the future course of social evolution in the United States and across many multiethnic and multilingual societies around the 
world. Although the future is fundamentally uncertain, one thing seems clear. For the foreseeable future, ethnic identity is likely to continue to be a ubiquitous, hotly debated, and politicized social-psychological phenomena. Intended or not, and directly or indirectly, researchers investigating ethnic identity and related issues are engaged in the ongoing identity polemics.

The present theoretical essay has been an attempt to help counterbalance, and thereby broaden, the prevailing pluralistic notions about ethnic identity. Based on a critical assessment of the pluralistic conceptions of ethnic identity, two interrelated ideologically based problematics, positivity bias and oversimplification, have been identified, along with some of the social scientific theories and research findings that document and explain the complexities in the way ethnic identity is enacted at the grassroots level of interethnic interface. A particular emphasis has been placed on the possibility of identity development from a monoethnic identity to a more interethnic identity, from a categorical identity to a more flexible and inclusive identity of individuated and universalized self-other orientation. The process of identity transformation brings with it an increased possibility for us to focus less on ascribed social categories and more on the attributes and conducts of each person as a unique individual and as a worthy fellow human being, to paraphrase Martin Luther King Jr. This evolutionary conception of identity projects a model of personhood that promotes social and cultural cohesion in the face of the challenges of interfacing of divergent ethnic identities.

To move in this new direction calls for an examination of the experiences of numerous everyday folks who, willingly or by necessity, engage in interethnic communication activities and understand that cross-borrowing of identities is often an act of appreciation that leaves neither the lender nor the borrower deprived, symbolically or otherwise. An extensive body of studies reporting on the acculturation and assimilation of immigrants offers a broad and general, if not direct, support for the present notion of identity adaptation and transformation. Suro (1998), for instance, reported that in the long term, Hispanics showed diminished Hispanic "cultural scripts" in their judgments and increased social interactions with non-Hispanics. In a study of language maintenance and shifts by Morgan (1987), Haitian migrants in the Dominican Republic are reported to have shifted, over time, from their native language, Creole, to the local language, Spanish. A similar progressive convergence of the "subjective meaning system" of Puerto Ricans in New York toward that of Anglo Americans was found by Szalay and Inn (1988). Likewise, Murphy-Shigematsu (1987) reported that Amerasians with first-generation Japanese mothers and White American fathers have struggled with their mixed racial and cultural conditions and have succeeded in forming their authentic identity in society. Another study by Dasgupta (1983) indicated that Asian Indian immigrants were able to resolve the conflict between their traditional value of holism and ascription and the American values of individualism, achievement, and competition by dichotomizing and attaining a healthy balance between primary in-group relationships and achievement in their occupational lives in the larger society. 
A broader indication of identity adaptation and transformation can be found in the attitudes and opinions of the American public at large concerning ethnic identity and interethnic relations in the United States. Despite the contentious identity polemics dominating media headlines, identity orientations of the majority of American people today show some degree of adaptation to the increasingly interethnic social environment. Straddled between the poles of traditional assimilationism and the counterpole of pluralism, the majority of Americans have been making strides in reconciling the two ideological poles and rejecting any ideological extremes. Theirs is an ideological position commonly referred to as integrationism, which emphasizes the need to accommodate the ideals of pluralism into those of assimilationism.

This observation is consistent with the conclusion Wolfe (1998) made when he characterized "the new middle-class morality" in the United States. Based on 200 indepth interviews conducted in the Boston, Atlanta, Tulsa, and San Diego metropolitan areas, Wolfe found "little support for the notion that middle-class Americans are engaged in bitter cultural conflict with one another" (p. 278). Instead, they are "struggling to find ways in which their core beliefs can be reconciled with experiences that seem to contradict them" (p. 281), while insisting on a set of values "capacious enough to be inclusive but demanding enough to uphold standards of personal responsibility" (p. 322). Wolfe's conclusion is supported by findings from the author's own study among university students and nonstudent adult residents (Kim, Kim, Duty, \& Yoshitake, 2002; Kim, McClure, Ogawa, \& Kim, 2003) and among Native Americans in Oklahoma (Kim, Lujan, \& Dixon, 1998). Results show that there are strong, positive feelings, regardless of one's ethnic background, toward one's own ethnic identity and toward American identity and that the feelings toward the two identities are positively correlated. The predominant ideological orientation is found to be a moderate integrationist one located in the middle of the assimilationismpluralism continuum. Most respondents further expressed concerns about rigid ethnic identity claims by some Americans.

Identity development of a person is not limitless, of course. The outer limit may be found where the balance between the stress engendered by intercultural challenges and the adaptive capacity that a given person is capable of mustering up. This means that, in the process of identity transformation, the aim must be to strike a balance between stress and adaptation, novelty and confirmation, change and stability (Jantsch, 1980). Because the optimal point of such balance varies from person to person, interethnic identity development must be ultimately "the gift of the individuals" (Steele, 1990, p. 171). Indeed, the survival and the quality of life of ethnically diverse societies must hinge on those individuals whose identities reach beyond a single ethnic category. They are among the ones who can provide the hub and glue of the inclusive moral infrastructure that can hold together divergent groups, facilitate individual freedom, discourage excessive identity claims, and help build a communal identity in which disparate identities are given their respective places without losing sight of common aspirations. They are among the ones who can better meet 
the enormous challenge that confronts us all — that is, "to give not only yourself but your culture to the planetary view" (Campbell, 1988, p. 114).

\section{References}

Alba, R. (1990). Ethnic identity: The transformation of White America. New Haven, CT: Yale University Press.

Amerikaner, M. (1978). Personality integration and the theory of open systems: A cross-subcultural approach. Unpublished doctoral dissertation, University of Florida, Gainsville.

Berry, J. (1980). Acculturation as varieties of adaptation. In A. Padilla (Ed.), Acculturation: Theory, models and some new findings (pp. 9-25). Washington, DC: Westview.

Berry, J. (1990). Psychology of acculturation: Understanding individuals moving between cultures. In R. Brislin (Ed.), Applied cross-cultural psychology (pp. 232-253). Newbury Park, CA: Sage.

Billig, M. (1987). Arguing and thinking: A rhetorical approach to social psychology. New York: Cambridge University Press.

Billig, M., Condor, S., Edwards, D., Gane, M., Middleton, D., \& Radley, A. (1988). Ideological dilemmas: A social psychology of everyday thinking. London: Sage.

Boekestijn, C. (1988). Intercultural migration and the development of personal identity: The dilemma between identity maintenance and cultural adaptation. International Journal of Intercultural Relations, 12, 83-105.

Brewer, M., \& Miller, N. (1984). Beyond the contact hypothesis: Theoretical perspectives on desegregation. In N. Miller \& M. Brewer (Eds.), Groups in contact: The psychology of desegregation (pp. 281-302). New York: Academic Press.

Campbell, J. (with Moyers, B.). (1988). The power of myth. New York: Doubleday.

Dasgupta, S. (1983). Indian immigrants: The evolution of an ethnic group. Unpublished doctoral dissertation, University of Delaware, Newark.

De Vos, G. (1990a). Conflict and accommodation in ethnic interactions. In G. A. De Vos \& M. SuarezOrozco (Eds.), Status inequality: The self in culture (pp. 204-245). Newbury Park, CA: Sage.

De Vos, G. (1990b). Preface. In G. A. De Vos \& M. Suarez-Orozco (Eds.), Status inequality: The self in culture (pp. 9-15). Newbury Park, CA: Sage.

Diesing, P. (1991). How does social science work? Reflections on practice. Pittsburgh, PA: University of Pittsburgh Press.

Erikson, E. (1950). Childhood and society. New York: Norton.

Erikson, E. (1968). Identity, youth, and crisis. New York: Norton.

Etzioni, A. (1993). The spirit of community: Rights, responsibilities, and the Communitarian agenda. New York: Crown.

Gallois, C., Ogay, T., \& Giles, H. (2005). Communication accommodation theory. In W. B. Gudykunst (Ed.), Theorizing about intercultural communication (pp. 121-148). Thousand Oaks, CA: Sage.

Garza, R., DeSipio, L., Garcia, F. C., Garcia, J., \& Falcon, A. (1992). Latino voices: Mexican, Puerto Rican and Cuban perspectives on American politics. Boulder, CO: Westview.

Giordano, J. (1974). Ethnicity and mental health: Research and recommendations. New York: Institute on Pluralism and Group Identity.

Glazer, N., \& Moynihan, D. (1963). Beyond the melting pot. Cambridge, MA: MIT Press.

Glazer, N., \& Moynihan, D. (1975). Ethnicity: Theory and experience. Cambridge, MA: Harvard University Press.

Graff, G. (1992). Beyond the culture wars: How teaching the conflicts can revitalize American education. New York: Norton.

Greeley, A. (1974). Ethnicity in the United States: A preliminary reconnaissance. New York: Wiley. 
Hacker, A. (1992). Two nations: Black and White, separate, hostile, unequal. New York: Scribner.

Hammersley, M. (1995). The politics of social research. London: Sage.

Hansel, B. (1993, December). An investigation of the re-entry adjustment of Indians who studied in the U.S.A. (Occasional Papers in Intercultural Learning No. 17). New York: AFS Center for the Study of Intercultural Learning.

Imahori, T., \& Cupach, W. (2005). Identity management theory: Facework in intercultural relationships. In W. Gudykunst (Ed.), Theorizing about intercultural communication (pp. 195-210). Thousand Oaks, CA: Sage.

Jantsch, E. (1980). The self-organizing universe: Scientific and human implications of the emerging paradigm of evolution. New York: Pergamon.

Kim, Y. Y. (1988). Communication and cross-cultural adaptation: An integrative theory. Clevedon, UK: Multilingual Matters.

Kim, Y. Y. (1995). Identity development: From cultural to intercultural. In H. Mokros (Ed.), Information and behavior: Interaction and identity (Vol. 6, pp. 347-369). New Brunswick, NJ: Transaction.

Kim, Y. Y. (1997). The behavior-context interface in interethnic communication. In J. Owen (Ed.), Context and communication behavior (pp. 261-291). Reno, NV: Context Press.

Kim, Y. Y. (1999). Unum and pluribus: Ideological underpinnings of interethnic communication in the United States. International Journal of Intercultural Relations, 23, 591-611.

Kim, Y. Y. (2001). Becoming intercultural: An integrative theory of communication and cross-cultural adaptation. Thousand Oaks, CA: Sage.

Kim, Y. Y. (2002). Unum vs. pluribus: Ideology and differing academic conceptions of ethnic identity. In W. Gudykunst (Ed.), Communication yearbook 26 (pp. 298-325). Mahwah, NJ: Lawrence Erlbaum.

Kim, Y. Y. (2005a). Adapting to a new culture: An integrative communication theory. In W. Gudykunst (Ed.), Theorizing about intercultural communication (pp. 375-400). Thousand Oaks, CA: Sage.

Kim, Y. Y. (2005b). Association and dissociation: A contextual theory of interethnic communication. In W. Gudykunst (Ed.), Theorizing about intercultural communication (pp. 323-349). Thousand Oaks, CA: Sage.

Kim, Y. Y., Kim, Y. S., Duty, D., \& Yoshitake, M. (2002, November). Patterns of interethnic communication among university students: A survey. Paper presented at the National Communication Association Convention, New Orleans, LA.

Kim, Y. Y., Lujan, P., \& Dixon, L. (1998). "I can walk both ways": Identity integration of American Indians in Oklahoma. Human Communication Research, 25, 252-274.

Kim, Y. Y., McClure, R. R., Ogawa, N., \& Kim, Y. S. (2003, May). Patterns of interethnic communication among adult Americans: A triangulation of quantitative and qualitative data. Paper presented at the annual conference of the International Communication Association. San Diego, CA.

Lazarus, R. (1966). Psychological stress and the coping process. New York: McGraw-Hill.

Lind, M. (1995). The American nation: The new nationalism and the fourth American revolution. New York: Free Press.

Louri, G. (1993). Free at last? A personal perspective on race and identity in America. In G. Early (Ed.), Lure and loathing (pp. 1-12). New York: Allen Lane/Penguin.

Morgan, N. (1987, December). Language maintenance and shift among Haitians in the Dominican Republic. Unpublished doctoral dissertation, University of New Mexico, Albuquerque.

Murphy-Shigematsu, S. (1987). The voices of Amerasians: Ethnicity, identity, and empowerment in interracial Japanese Americans (Doctoral dissertation, Harvard University, 1987). Dissertation Abstracts International, 48(04), 1143B.

Nash, M. (1989). The cauldron of ethnicity in the modern world. Chicago: University of Chicago Press.

Novak, M. (1971). The rise of the unmeltable ethnics. New York: MacMillan.

Oddou, G., \& Mendenhall, M. (1984). Person perception in cross-cultural settings. International Journal of Intercultural Relations, 8, 77-96. 
Parenti, M. (1967). Ethnic politics and the persistence of ethnic voting identification. American Political Science Review, 67, 717-726.

Pettigrew, T. (1988). Integration and pluralism. In P. Katz \& D. Taylor (Eds.), Eliminating racism: Profiles in controversy (pp. 19-30). New York: Plenum.

Roosens, E. (1989). Creating ethnicity: The process of ethnogenesis. Newbury Park, CA: Sage.

Root, M. (1993). Within, between, and beyond race. In M. Root (Ed.), Racially mixed people in America (pp. 3-11). Newbury Park, CA: Sage.

Schuetz, A. (1944/1963). The stranger: An essay in social psychology. In M. Stein \& A. Vidich (Eds.), Identity and anxiety survival of the person in mass society (pp. 98-109). Glencoe, IL: Free Press.

Simmel, G. (1908/1950). The stranger. In K. H. Wolff (Ed. and Trans.), The sociology of Georg Simmel (pp. 402-408). New York: Free Press.

Slavin, M., \& Kriegman, D. (1992). The adaptive design of the human psyche. New York: Guilford.

Smolowe, J. (1993, fall). Intermarried . . . with children: The new face of America. Time, pp. 64-65.

Steele, S. (1990). The content of our character: A new vision of race in America. New York: Harper Perennial.

Stonequist, E. (1937). The marginal man. New York: Scribner.

Stonequist, E. (1964). The marginal man: A study in personality and culture conflict. In E. Burgess \& D. Bogue (Eds.), Contributions to urban sociology (pp. 327-345). Chicago: University of Chicago Press.

Suro, R. (1998). Strangers among us: How Latino immigration is transforming America. New York: Knopf.

Szalay, L., \& Inn, A. (1988). Cross-cultural adaptation and diversity: Hispanic Americans. In Y. Y. Kim \& W. B. Gudykunst (Eds.), Cross-cultural adaptation: Current approaches (pp. 212-232). Newbury Park, CA: Sage.

Taft, R. (1977). Coping with unfamiliar cultures. In N. Warren (Ed.), Studies in cross-cultural psychology (Vol. 1, pp. 121-153). London: Academic Press.

Tajfel, H. (1974). Social identity and intergroup behavior. Social Science Information, 223(2), 96-102.

Tajfel, H. (1978). Social categorization, social identity and social comparison. In H. Tajfel (Ed.), Differentiation between social groups (pp. 61-76). New York: Academic Press.

Tajfel, H., \& Turner, J. (1979). An integrative theory of intergroup conflict. In W. Austin \& S. Worchel (Eds.), The social psychology of intergroup relations (pp. 33-47). Monterey, CA: Brooks/Cole.

Tajfel, H., \& Turner, J. (1986). The social identity theory of intergroup behavior. In S. Worchel \& W. Austin (Eds.), Psychology of intergroup relations (pp. 7-17). Chicago: Nelson-Hall.

Thornton, M. (1996). Hidden agendas, identity theories, and multiracial people. In M. Root (Ed.), The multiracial experience: Racial borders as the new frontiers (pp. 101-120). Thousand Oaks, CA: Sage.

Ting-Toomey, S. (1993). Communicative resourcefulness: An identity negotiation perspective. In R. Wiseman \& J. Koester (Eds.), Intercultural communication competence (pp. 72-111). Newbury Park, CA: Sage.

Ting-Toomey, S. (2005). Identity negotiation theory: Crossing cultural boundaries. In W. B. Gudykunst (Ed.), Theorizing about intercultural communication (pp. 211-233). Thousand Oaks, CA: Sage.

Toffler, A. (1980). The third wave. New York: Bantam Books.

Traub, J. (1998, June 28). Nathan Glazer changes his mind, again. The New York Times Magazine, pp. 22-25.

Tsuda, Y. (1986). Language inequality and distortion in intercultural communication: A critical theory approach. Amsterdam: John Benjamins.

Turner, J., Hogg, M., Oakes, P., Reicher, S., \& Wetherell, M. (1987). Rediscovering the social group: A self-categorization theory. Oxford, UK: Basil Blackwell.

Wolfe, A. (1998). One nation, after all. New York: Viking.

Wolfinger, R. (1965). The development and persistence of ethnic voting. American Political Science Review, 59, 896-908.

Yinger, J. (1986). Intersection strands in the theorisation of race and ethnic relations. In J. Rex \& D. Mason (Eds.), Theories of race and ethnic relations (pp. 20-41). New York: Cambridge University Press. 
300 Journal of Language and Social Psychology

Yoshikawa, M. (1978). Some Japanese and American cultural characteristics. In M. Prosser (Ed.), The cultural dialogue: An introduction to intercultural communication (pp. 220-239). Boston, MA: Houghton Mifflin.

Young, R. (1996). Intercultural communication: Pragmatics, genealogy, deconstruction. Philadelphia: Multilingual Matters.

Young Yun Kim (PhD, Northwestern University, 1976) is a professor of communication at the University of Oklahoma. She teaches courses and conducts research in intercultural and interethnic communication. Her recent publications include Becoming Intercultural (2001) and Communicating With Strangers (4th ed., 2003, with W. Gudykunst). 